\title{
HALDUSTEKSTI STRUKTUURIST TARTU LINNAVALITSUSE KORRALDUSTE NÄITEL
}

\section{Katrin Mandra}

Ülevaade. Artiklis vaadeldakse Tartu Linnavalitsuse korralduste näitel, milline on sellistes haldustekstides lause süntaktiline struktuur ning mis tähendusi struktuurist lähtuvalt korraldustele omistada võib. Haldustekste ei ole tekstiliigi seisukohast palju uuritud, mistõttu ongi huvitav ajakirjandustekstide ja õigustekstide kõrval välja selgitada haldustekste iseloomustavad erijooned. Autorit huvitab korraldustes esitatud otsuste süntaks, funktsionaalsete protsesside ja protsessiosaliste väljendamise viisid. Protsessiliike vaadeldakse eesmärgiga välja selgitada, kas verbide primaarne leksikaalne tähendus ja korralduskontekstis representeeritav tegevustähendus langevad kokku. Agendianalüüsi eesmärgiks on osaliste tegelike sotsiaalsete rollide ja tekstis esitatavate grammatiliste rollide võrdlus - kas ja kuivõrd nad ühilduvad mis tegevusi neile omistatakse.*

Võtmesõnad: tekstilingvistika, tekstiliik, funktsionaalne grammatika, süntaks, eesti keel

\section{Sissejuhatus}

Haldustekste loovad ja kasutavad seadusandlik, täidesaatev ja kohtusüsteem. Halduse keele all mõistetakse haldussüsteemi kirjalikku keelekasutust ja haldusdokumentide keelekasutust. Haldusdokumendil on järgmised funktsioonid: tõendamine, info edastamine, info liigendamine ja korrastamine. Tõendusfunktsiooniga haldusdokumente vormistatakse praegu paberil, informatiivse funktsiooniga haldusdokumendid võivad esineda ka ainult elektroonilisel kujul. (Kukk 2003: 96)

Artikli analüüsimaterjal on pärit avalikust dokumendiregistrist Tartu Linnavalitsuse koduleheküljel. ${ }^{1}$ Uurimisobjektiks on valitud korraldused, sest materjalihulk on selgesti piiritletav, piisavalt mahukas ning kergesti ligipääsetav. Tüüpiline korraldus koosneb kahest poolest - esimeses ehk preambulis esitatakse korralduse

* Artikkel on valminud Eesti Teadusfondi grandi nr 6236 osalisel toel. 
aluseks olev seadustekst ja teises osas on kirjas seadusest lähtuv otsus. Siinses artiklis vaadeldakse korralduse teist poolt ehk seda, kuidas on esitatud korralduses sisalduv otsus. Fookusesse on võetud kolm küsimust:

1) milline on korralduse otsuseosa süntaktiline struktuur;

2) milline on otsuse sisu, s.t direktiivsete protsesside funktsionaalne liigitus;

3) kes peab korralduse täitma, s.t kas ja kuidas on esitatud deontilisuse agent.

Analüüsi materjaliks on 2007. aasta novembris registreeritud korraldused, mida kokku oli 91. Lauseid, mis otseselt andsid korralduse, otsustasid midagi, oli kokku 206. Valim on koostatud lähtudes artikli eesmärgist, s.t korraldusteksti otsustusosa laused on oma olemuselt direktiivsed, sest neis fikseeritakse kellelegi antav korraldus. Protsesside funktsionaalne liigitus näitab, milliste verbidega korraldusi esitatakse ja milline on nende verbide tegevustähendus. Korralduste agendianalüüs annab valimis ülevaate, kes on protsessiosalised, kuidas vormistatakse neid grammatiliselt ja milline on nende tegelik sotsiaalne roll.

Töö teoreetiline raamistik toetub M. A. K. Halliday funktsionaalsele grammatikale, Roger Fowleri käsitlusele protsessiliikidest ja protsessiosalistest, viimaste osas ka Theo van Leeuweni seisukohtadele. Iga vaatenurga teoreetiline taust esitatakse vastava osa alguses.

\section{Korralduste otsuslausete sūntaks}

Siinse ülevaate eesmärgiks on näidata, milline on tüüpiline korraldustekstis esitatav otsuslause ja kui püsiv või varieeruv on selle ülesehitus. Otsuslausete lauseehitus on aluseks hilisemale protsessi ja agendianalüüsile. Eristuvad kolm struktuuritüüpi. Kõik otsuslaused sisaldavad subjektist ja predikaadist koosnevat pealauset Tartu linnavalitsus otsustab, millele järgneb koolon. Korraldust ennast esitav osa on vormistatud sekundaarse verbitarindina, mille peasõnaks on $d a$-infinitiiv $(1,2)$, või kõrvallausena, mille alguses puudub alistav sõna (3), nt

(1) (Tartu Linnavalitsus otsustab): moodustada alates 3. detsembrist 2007. a Tartu Lasteaed Lotte juhataja asetäitja õppe- ja kasvatustöö alal ametikoht. (27.11.2007. a nr 1383)

(2) (Tartu Linnavalitsus otsustab): arhitektuuri ja ehituse osakonnal avaldada kahe nädala jooksul informatsioon kasutusloa andmise kohta ajalehes Postimees ja Tartu linna koduleheküljel. (27.11.2007. a nr 1397)

(3) (Tartu Linnavalitsus otsustab): koosseisuväliste ametikohtade teenistustähtaega pikendatakse järgmiselt .. (27.11.2007. a nr 1393)

$d a$-infinitiivi juurde võib kuuluda adessiivis agentadverbiaal (2) või mitte (1). Statistiliselt esineb otsustes kõige enam tüüpi (1) näiteid, järgnevad tüüpi (2) ja kõige vähem on (3) variante. Korraldustekstide laused on erineva keerukusastmega, sõltuvalt sellest, kui palju ja missugust infot peale korralduse sisu määrava verbi ja korralduse adressaadi neis lausetes veel sisaldub. Siinses artiklis sellele aspektile ei keskenduta, ent illustratsiooniks olgu esitatud mõned näitelaused, millest on näha, et silmatorkavalt palju esineb sisestatud konstruktsioone, eriti sekundaarse poolt-agendiga passiivseid partitsiiptarindeid, nominalisatsioone ja viiteid teistele 
dokumentidele, mis muudavad lausest arusaamise keerukaks, kuna ühte lausesse mahutatakse sel viisil palju informatsiooni.

(4) (Tartu Linnavalitsus otsustab): kooskõlastada Raudteeinspektsiooni poolt esitatud ehitusloa taotlus $\mathrm{nr} 1065610$ Tartu raudteejaama reisijate ooteplatvormi rekonstrueerimiseks ja ASi Eesti Raudtee poolt koostatud ehitusprojekt "Tartu raudteejaam. Reisijate ääreooteplatvorm" (töö nr E 03-07). (06.11.2007. a nr 1338)

(5) (Tartu Linnavalitsus otsustab): korrigeerida planeeringut vastavalt Tartu Linnavalitsuse 2. oktoobri 2007. a korraldusele nr 1183 "Seisukoha võtmine Vahi 62 krundi ja lähiala detailplaneeringu avaliku väljapaneku jooksul laekunud ettepanekute ja vastuväidete osas, detailplaneeringu avaliku arutelu aja ja koha määramine ning detailplaneeringu keskkonnamõju strateegilise hindamise algatamata jätmine" ning arvestades järgnevaid märkusi .. (06.11.2007. a nr 1335)

(6) (Tartu Linnavalitsus otsustab): korralduses märgitud eesmärkide saavutamiseks anda linnaplaneerimise ja maakorralduse osakonna juhatajale UA-le õigus kinnistute ühendamiseks, katastriandmete muutmiseks ja uute katastriandmete alusel kinnistute jagamiseks ning ettenähtud võla-ja asjaõiguslepingute sõlmimiseks, samuti Tartu linna nimel vajalike dokumentide allakirjutamiseks. (06.11.2007. a $\mathrm{nr}$ 1332)

Kõikide näidete puhul on lausestusaste kõrge, s.t ühte lausesse on koondatud nii palju protsesse, et nende eristamine ja lausest arusaamine on raskendatud. On kujunenud kindlad lausemallid, millega otsuseid esitatakse. Kaks silmatorkavamat süntaktilist tunnust on, et osalausete eraldamiseks kasutatakse harva sidesõnu ja et kogu edastatav info tahetakse mahutada ühte lausesse.

\section{Korralduste otsuslausete funktsionaalsed rūhmad}

Eespool selgus, et korraldused vormistatakse kas sekundaarse verbitarindina, mille peasõnaks on $d a$-infinitiiv koos adessiivis agentadverbiaaliga või ilma selleta, või kõrvallausena, mille algusest puudub sidend. Sellest lähtub järgnev funktsionaalsete rühmade liigitus: millist tähendust otsuslause esitab, kui tema peasõnaks on $d a$-infinitiiv, ning millist rolli mängib sidendi puudumine otsuslause tähenduse seisukohast.

$d a$-infinitiiv võib olla käsku väljendava lause predikaadiks (Mitte suitsetada! Jutt jätta! - vt nt Metslang 2004: 243-255). Samas on see üsna tavaline verbilaiend. Mati Erelt (1984:4) defineerib da-infinitiivi kui sekundaarset predikaati, mis edastab sõltuvat, sisestatud, sekundaarset tegevust. Et korraldustes eelneb $d a$-infinitiivile koolon, rõhutab see $d a$-infinitiivi positsiooni iseseisva lause predikaadina, mitte sekundaarse verbilaiendina (vrd Tartu linnavalitsus otsustab korraldada näituse .. Tartu linnavalitsus otsustab: korraldada näitus ..). Vaatlen järgnevalt, millise tähendusega $d a$-infinitiivis verbe korraldustes kasutatakse. Verbide primaarne leksikaalne tähendus ja korralduskontekstis representeeritav tegevustähendus ei lange alati kokku. Verbe liigitan funktsionaalsete protsesside järgi. 
Protsesside liikide kohta on tuntuima käsitluse esitanud M. A. K. Halliday (1994: 88-92), kes oma funktsionaalses grammatikas eristab tekstina edastatavas situatsioonis kolme kategooriat: osalisi (ingl participant), protsesse (process) ning tingimusi (circumstance). Protsessi all mõistab Halliday sündmust, mis keelendatakse lauseks järgmiste küsimuste abil: "kes tegi mida, kus, millal, kuidas ja kellele”. Halliday järgi saab eristada kolme põhiprotsessi, milleks on materiaalsed, mentaalsed ja suhteprotsessid. Materiaalsed protsessid konstrueerivad tegelikku või kujuteldavat muutust, liikumist või tegevust. Neil on tavaliselt mingi konkreetne, tajutav tulemus. Halliday liigitab materiaalseteks ka abstraktsed tegevused ja sündmused. Mentaalsed protsessid väljendavad mõtlemist, tundmist, tahtmist, tajumist ning suhteprotsessid kirjeldavad seisundit või olemist.

Oma protsessiliigituse on välja töötanud ka Roger Fowler, kes toetub Hallidayle ja kelle liigitus on n-ö modifikatsioon Halliday omast. Tekstis eristab Fowler järgmisi kategooriaid: tegevus (ingl action), protsess (process) ja seisund (state). Esimese puhul keegi teeb midagi, teise puhul midagi toimub ja kolmas lausetüüp annab edasi staatilist olukorda. Kõik need kategooriad omakorda võivad esineda kas materiaalsete, mentaalsete või verbaalsetena. (Fowler 1991: 73-74) Siinses artiklis toetutakse protsesside liigitamisel mõlemale autorile, eristades 1) materiaalseid (sh konkreetseid ja abstraktseid), 2) mentaalseid, 3) suhte- ehk seisundiprotsesse ning 4) verbaalseid protsesse.

Selgub, et korralduste funktsioonid on erinevad sõltuvalt sellest, kas korralduse adressaat on linnavalitsus ise või keegi teine, keda kohustatakse. Neis näitelausetes, kus deontilisuse autoriteet (korralduse andja) ja deontilisuse agent (korralduse adressaat, vt järgmist peatükki) on erinevad, on ülekaalus konkreetsed materiaalsed protsessid. Alljärgnevates näideteski on variandis (7) arhitektuuri ja ehitusosakonnal kohustus avaldada oluline info meedias, samuti on ära määratud ajavahemik, millal korraldus peab täidetud olema. Konkreetsel tegevusel peab olema konkreetne resultaat. Samuti on näites (8), kus allüksusel tuleb korraldada registreering katastris. See on samuti tegevus, millel on reaalne resultaat ja on lihtsalt kontrollitav, kas registreering on muudetud või mitte. Ka näites (9) on selline korraldus, kus linnamajanduse osakond peab esitama konkreetse paberi selleks, et saada mingi rahasumma. Tegemist on taas korraldusega teha mingi reaalne tegu, mille väljundiks on konkreetne dokument.

(7) (Tartu Linnavalitsus otsustab): Arhitektuurija ehitusosakonnal avaldada kahe nädala jooksul informatsioon ehitusloa väljastamise kohta ajalehes Postimees ja Tartu linna koduleheküljel. (06.11.2007. a nr 1326)

(8) (Tartu Linnavalitsus otsustab): Linnaplaneerimise ja maakorralduse osakonnal korraldada Turu tn 45D katastriüksuse sihtotstarbe muutmise registreerimine maakatastris. (06.11.2007. a $\mathrm{nr}$ 1327)

(9) (Tartu Linnavalitsus otsustab): Linnamajanduse osakonnal esitada taotlus raha eraldamiseks 2007. a reservfondist p 1 nimetatud lepingu ettemaksu ja I osamaksu katteks summas 40120 (nelikümmend tuhat ükssada kakskümmend) krooni. (27.11.2007. a nr 1390)

Mitmekülgsem on protsesside pilt lausetes, kus deontiline autoriteet ja deontiline agent langevad kokku: linnavalitsus määrab, mida ta ise peab tegema. Ka selles rühmas on ülekaalus materiaalsed protsessid. Samas on tähelepanuväärne see, et 
erinevalt eelmisest rühmast väljendab väga suur hulk neist tegelikult abstraktseid materiaalseid tegevusi. Ilmnes, et neil juhtudel, kui korralduses fikseeritakse mõni tegevus, mis on suunatud linnavalitsusele endale, ei pruugi verbi primaarne leksikaalne tähendus ja korralduskontekstis representeeritav tegevustähendus kokku langeda.

(10) (Tartu Linnavalitsus otsustab): võtta informatsioon Vahi 62 krundi ja lähiala detailplaneeringu avaliku väljapaneku tulemusi tutvustava avaliku arutelu tulemuste kohta teadmiseks. (06.11.2007. a nr 1335)

(11) (Tartu Linnavalitsus otsustab): moodustada alates 3. detsembrist 2007. a Tartu Lasteaed Lotte juhataja asetäitja õppe- ja kasvatustöö alal ametikoht. (27.11.2007. a $\mathrm{nr}$ 1383)

(12) (Tartu Linnavalitsus otsustab): muuta Pikk tn 60, 64 katastriüksuse (katastritunnus 79514:028:0009, registriosa $\mathrm{nr}$ 436403, sihtotstarve 100\% ühiskondlike hoonete maa) sihtotstarvet ning määrata uueks

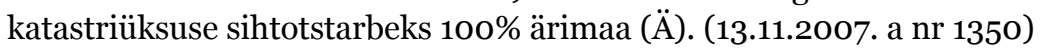

Kõigi kolme näitelause verbid tähistavad materiaalseid protsesse: võtma, moodustama, muutma. Lausekontekstis saavad nad aga teise tähenduse ning muutuvad kasutatud konstruktsioonis konkreetsetest abstraktseteks. Näites (10) on materiaalne võtma konstruktsioonis võtma teadmiseks tegelikult mentaalne. Näidetes (11) ja (12) saavad materiaalsed moodustama ja muutma konstruktsioonides moodustama ametikohta ja muutma sihtotstarvet aga abstraktse sisulise tähenduse. Korralduste kontekst muudab nad abstraktseteks, kuna reaalselt ei moodusta Tartu linnavalitsus ametikohta mujal kui paberil ning samamoodi toimub ka sihtotstarbe muutmine. Samuti esineb korraldustes selliseid näiteid, kus verbaalne tegevus osutub ütleja institutsionaalse võimurolli tõttu tegelikult reaalseks tegevuseks. Selliste funktsioonidega on lähemalt tegelenud kõnetegude teooria, vt nt Austin 1984: 94-164, Searle 1970: 22-50.

(13) (Tartu Linnavalitsus otsustab): nimetada perearsti nimistu moodustamise õiguse andmise konkursikomisjoni Tartu linna esindajaks tervishoiuosakonna juhataja SK. (06.11.2007. a nr 1315)

(14) (Tartu Linnavalitsus otsustab): nõustuda Narva mnt 84a maa erastamisega aadressil Narva mnt 84 paiknevate korteriomandite omanikele. (12.11.2007. a nr 1353)

(15) (Tartu Linnavalitsus otsustab): Keskkonnamõju hindamise algatamise otsusest teatada ametlikus väljaandes Ametlikud Teadaanded ja ajalehes Postimees 14 päeva jooksul. (20.11.2007. a nr 1367)

Primaarselt on kõigi kolme verbi (nimetama, nõustuma, teatama) tähendusväli verbaalne, ent korraldustes tähendab nii nimetamine, nõustumine kui ka teatamine reaalset tegevust, mille tulemusena reaalne isik SK kuulub komisjoni, kuhu ta enne ei kuulunud (näide 13), reaalsete isikute ring saab maaomanikeks (näide 14) ja otsus ilmub ajalehes (näide 15).

Korralduste otsuslauseid vaadeldi ka sellest seisukohast, mil määral sisaldub tekstides direktiivseid protsesse. Eesti keele direktiivverbe on uurinud Heili Orav oma magistritöös, toetudes direktiivverbe defineerides John R. Searle’ile, kelle 
järgi on direktiivse kõneakti taotluseks panna kedagi midagi tegema. Tüüpiliselt mõeldakse sellise definitsiooniga käske ja palveid (Orav 1998: 26). Linnavalitsuse korralduste puhul ilmnes tendents, et lausetes, kus agendiks oli Tartu Linnavalitsus, kasutati kõige sagedamini just direktiivverbe. Viis tavalisemat verbi korraldusnäidetes olid määrama (26 korda), volitama (20), tunnistama (15), sõlmima (13) ja kinnitama (10), millest kolm (määrama, volitama, kinnitama) võib liigitada direktiivverbideks. Põhjuseks on ilmselt korralduste olemus - jagada käske-korraldusi, teha otsuseid ja need fikseerida. Alljärgnevalt ka levinumate direktiivverbide lausenäited.

(16) Määrata Ravila tänav 65T kinnistule nimetuseks Klaasi tänav T5. (27.11.2007. a nr 1392)

(17) Volitada lepingut sõlmima linnaplaneerimise ja maakorralduse osakonna juhataja UA. (06.11.2007. a $\mathrm{nr}$ 1333)

(18) Kinnitada haridusosakonna 2007. a finantseerimis- ja majandamiseelarves ümberpaigutused vastavalt lisadele 1-2. (27.11.2007. a nr 1402)

Korralduste otsuslausete funktsionaalne analüüs näitas, et korralduste funktsioon sõltub sellest, kes on korralduse adressaadiks. Eristumine materiaalsete, mentaalsete ja verbaalsete protsesside vahel toimub vaid grammatiliselt. Verbi leksikaalne tähendus ja korraldustähendus langevad enamasti kokku, kui korralduse agent ja autoriteet on erinevad. Kui aga korraldus on suunatud autoriteedile endale, tekkivad erinevused verbi leksikonitähenduse ja korralduses esitatava tegevustähenduse vahel. Eraldi nüansi lisas otsuslausetele ka direktiivverbide vaatlus - neid esines palju, mis ei ole üllatav, arvestades korralduste direktiivset iseloomu.

\section{Korralduste otsuslausete protsessiosalised}

Korralduste protsessiosalistest vaatlen kaht rolli: deontilisuse autoriteeti ja deontilisuse agenti. Theo van Leeuwen viitab, et osaliste rollijaotuse uurimine on paljude kriitilise tekstianalüüsiga tegelejate huviobjektiks, nimetades Norman Fairclough'd, Rodger Fowler'it, Gunther Kressi ja Robert Hodge'i ning Teun A. van Dijki. Teema on neil kõigil üks: keda esitatakse kui agenti (ingl actor) ja mis on agendi tegevuse eesmärk ( $g o a l$ ). Küsimus on tekstiuurimises oluline, kuna osaliste tegelikud rollid sotsiaalses tegevuses ja grammatilised rollid, mida esitatakse tekstis, ei pruugi üldse ühilduda (Leeuwen 1996: 43).

Esitusviis võimaldab osalejatel olla kas aktiivsetes või passiivsetes rollides (Leeuwen 1996: 43). Aktiivses rollis on osaline siis, kui teda esitatakse kui tegevuse liikumapanevat jõudu, passiivne on osaline aga käimasolevas tegevuses või tegevuse vastuvõtva poolena, aga samuti on passiivne ka toimumisprotsesside ja seisundiprotsesside osaline. Deontilisuse autoriteet (Tartu Linnavalitsus otsustab ..) on korraldusteksti aktiivne osaline, deontilisuse agendil on kaksipidine roll: korralduse andja vaatepunktist on ta korralduse vastuvõtja ehk siis passiivne osaline, samas on ta süntaktiliselt sisestatud protsessi aktiivne tegija ehk see osaline, kes korralduse täidab.

Teine tähtis moment osaliste nimetamise ja kategoriseerimise juures on nende üldistamine ja identifitseerimine. Osalisi saab esitada kui üldistatud klasse 
(rühma, hulka jmt) või täpsustatud, identifitseeritavat osalist. Viimasel juhul on omakorda võimalik eristada identifitseerimist üksikisiku või rühmana (kodanikud, meie) või kvantitatiivselt piiritletud hulgana (kolm ministrit). Nii rühmi kui ka üksikisikuid on võimalik esitada kas indefiniitselt (indefiniitsete pronoomenite või impersonaali abil) või definiitselt (nimeliselt või funktsiooni ja identiteedi järgi). Indeterminatsiooniga on tegemist juhul, kui osalisi esitatakse täpsustamata, anonüümsete indiviidide või gruppidena; determinatsioonist saame rääkida siis, kui nende osaliste identiteet on ühel või teisel viisil täpsustatud. Tüüpiliselt väljendub indetermineeritus umbmääraste asesõnade abil, nt keegi, miski, mingi, mingisugune. Kategoriseerimist vaadeldakse põhiliselt kahest aspektist: kas osaline on määratletud tema tegevuse või isiklike omaduste kaudu. (Leeuwen 1996: 46, 51, Kasik 2006: 23)

Tartu Linnavalitsuse korraldustes on kõigile protsessiosalistele ühine see, et alati on tegemist kollektiivse osalisega, kelleks on kollektiivsubstantiiviga väljendatud institutsionaalne üksus. Protsessiosaliste vahel saab eristada kolmesuguseid suhteid: 1) Tartu Linnavalitsus esineb mõlemas rollis - ise ollakse nii autoriteet (korralduse andja) kui ka agent ehk korralduse täitja; 2) korralduse täitja on korralduse andjast erinev osaline, kelleks tavaliselt on linnavalitsuse allüksused, nt linnakantselei; 3) korraldustes esineb ka selliseid näiteid, kus on küll olemas autoriteet, kelleks alati on Tartu Linnavalitsus, ent agent on nimetamata.

Vaatluse all olnud korraldustest u 70\% otsuslausetes oli nii autoriteediks kui ka agendiks Tartu Linnavalitsus ise, seega on korraldus iseendale suunatud tegevuse fikseerimine, nt

(19) (Tartu Linnavalitsus otsustab): eraldada linnavalitsuse reservfondist kokku 74 ooo tuh krooni. (13.11.2007. a nr 1360)

(20) (Tartu Linnavalitsus otsustab): tunnistada kehtetuks Tartu Linnavalitsuse 04. septembri 2007. a korraldus nr 1057 "Korteriomandite ostmine". (27.11.2007. a nr 1387)

(21) (Tartu Linnavalitsus otsustab): osaleda juhtpartnerina projektis "Dendropargi matkaraja rajamine", mis esitatakse rahastamiseks Sihtasutusele Keskkonnainvesteeringute Keskus keskkonnaprogrammi raames. (13.11.2007. a nr 1348)

Näites (19) otsustab linnavalitsus, et peab eraldama raha, (20) puhul otsustab tunnistada enda varasema korralduse kehtetuks ning näites (21)fikseeritakse ära enda osalus projektis. Osalejate vaatlemise seisukohast on korraldused huvipakkuv materjal, sest ehkki tegemist on ametlike dokumentidega, kus määratakse ära eri poolte kohustused, on esitusviisis paras hulk ebamäärasust. Verbi laiendava $d a$-infinitiivitarindi korral on tegevussubjekt sama kui lause subjekt, juhul kui sekundaarse tegevuse subjekti eraldi ei märgita. Samas koolon pealause ja $d a$-infinitiiviga tarindi vahel võimaldab viimast käsitada omaette osalausena, kus da-infinitiivse predikaadiga kaasneb umbisikulisus, ühine subjekt eelneva lausega ei ole enam nii enesestmõistetav. Seega Tartu Linnavalitsus võib küll loogiliselt olla agendiks, ent kellele konkreetselt korraldus antakse, jääb sel juhul otsuses ühemõtteliselt fikseerimata. Korraldustes otsustatu tegematajätmise puhul on väga raske kedagi konkreetset vastutavaks teha.

Umbes 20\% lausenäidetes oli üheks osalejaks Tartu Linnavalitsuse allüksus. Autoriteetne linnavalitsus jagab käske oma allüksustele, vaid harvadel juhtudel 
on agent keegi muu kui linnavalitsuse allosakond. Süntaktiliselt on deontilisuse agent alati vormistatud adessiivivormis agentadverbiaalina. Antud materjalis domineerisid kolm agenti: arhitektuuri ja ehituse osakond (22), linnaplaneerimise ja maakorralduse osakond (23) ja haridusosakond (24).

(22) (Tartu Linnavalitsus otsustab): Arhitektuuri ja ehituse osakonnal väljastada ehitusluba Eha 11 krt 7 rekonstrueerimiseks. (06.11.2007. a $\mathrm{nr}$ 1326)

(23) (Tartu Linnavalitsus otsustab): Linnaplaneerimise ja maakorralduse osakonnal korraldada korrigeeritud detailplaneeringu lahenduse tutvustamiseks avalik arutelu. (06.11.2007. a nr 1335)

(24) (Tartu Linnavalitsus otsustab): Tartu Linnavalitsuse Haridusosakonnal on õigus teha kuni 01. detsembrini 2007. a. kontsernikonto vahenditest punktis 1 märgitud summa ulatuses väljamakseid. (13.11.2007. a $\mathrm{nr}$ 1342)

Nagu eespool märgitud, on tegevused, mille puhul linnavalitsus on vaid autoriteediks, oluliselt konkreetsemad võrreldes nende tegevustega, mida linnavalitsus endale suunatud korraldustes näitab. Näidetes (22) ja (23) esitatakse reaalsed tegevused, mida üks või teine osakond peab ära tegema. Näites (24) annab linnavalitsus oma osakonnale õiguse teatud summadega opereerimiseks. Kuna tegevused, mida esitatakse, on konkreetsed ja osalejadki on konkreetsemad kui eelmises näideteplokis esitatud Tartu Linnavalitsus, siis on neil osalejatel ka suurem vastutus. Osakond on kitsam üksus kui linnavalitsus tervikuna, ent kedagi individualiseeritult agendina ka ei nimetata.

Kõige vähem esines uuritud materjalis selliseid näiteid, kus agent oli nimetamata. Need näited moodustasid u 10\% kogu materjalist. Võiks eeldada, et neid näiteid, kus agenti pole nimetatud, on võimalik tõlgendada nii, et see on linnavalitsus ise, ent tegelikult selgub korralduse ülejäänud tekstist, et agent on olemas, ehkki ta pole esitatud konkreetselt selles otsuslauses:

(26) (Tartu Linnavalitsus otsustab): korrigeeritud planeerimislahendus esitada Tartu Linnavalitsusele avaliku väljapaneku korraldamiseks. (20.11.2007. a nr 1377)

(27) (Tartu Linnavalitsus otsustab): planeeringu eskiislahendust tutvustada linnavolikogu arengu- ja planeerimiskomisjonis. (20.11.2007. a nr 1378)

Niisiis iseloomustab protsessiosalisi kollektiivsus: osalejad on pea eranditult institutsionaalsed kollektiivsed üksused, kes omavad otsuslausetes kolmesuguseid suhteid. Kuna suurema osa analüüsimaterjalist moodustasid sellised laused, kus nii autoriteet kui agent oli Tartu Linnavalitsus ise, siis näitab see ühelt poolt endale suunatud korralduste andmist, teiselt poolt aga seda, et päris täpselt ei öelda, kellele korraldus antakse. Väiksema rühma moodustasid sellised näited, kus agendiks oli linnavalitsuse allüksus, selline korraldus on konkreetsem, ent allüksus ei ole siiski konkreetne isik. Kõige vähem oli näiteid, kus agent oli nimetamata. Samas varasemast tekstist saab aru, et selleks pole mitte linnavalitsus ise, vaid keegi anonüümne tegija. Agendikasutuse järgi saab korraldust iseloomustada kui teksti, mis ühelt poolt on dokument, mis fikseerib kohustusi, teisalt aga ei ütle konkreetselt, kes peab tegema, kes on vastutav. 


\section{Kokkuvõte}

Artiklis on vaadeldud korralduslausete süntaksit ning sellest lähtuvalt protsessiliike ja -osalisi. Analüüsitud korralduste süntaksit iseloomustab vormiliselt üheks lauseks liidetud protsesside suur hulk. Seetõttu on lausetes palju infinitiiv-ja partitsiiptarindeid ning nominalisatsioone, mis teeb laused pikaks ja struktuurilt keeruliseks.

Verbidega edastatavate protsesside liigid on seostes protsessiosalistega. Lausetes, kus agendiks on linnavalitsuse allüksused, on otsuslausetes ülekaalus konkreetsed materiaalsed protsessid. Kui nii korralduse andjaks kui ka täitjaks on Tartu Linnavalitsus ise, siis on otsustena vormistatud protsessid abstraktsemad ja sagedamini mentaalsed või verbaalsed. Vaadeldi ka, kas verbide primaarne leksikaalne tähendus ja korralduskontekstis representeeritav tegevustähendus langevad kokku. Linnavalitsuse kui võimuinstitutsiooni iseloomu tõttu osutub verbaalne tegevus paljudel juhtudel reaalseks tegevuseks.

Agendianalüüsi eesmärgiks on osaliste tegelike sotsiaalsete rollide ja tekstis esitatavate grammatiliste rollide võrdlus: kas ja kuivõrd nad ühilduvad, mis tegevusi neile omistatakse. Korralduste otsuslausete protsessiosaliste puhul on üheks pooleks, autoriteediks kõikidel juhtumitel Tartu Linnavalitsus. Enamasti ongi ka korralduste otsused suunatud linnavalitsusele endale, mis samas muudab vastutuse otsuste eest häguseks. Väiksem osa korralduste otsuseid on suunatud mõnele linnavalitsuse allüksusele ning sel juhul on ka tegevused konkreetsemad. Kui korralduse täitja on selle andjast erinev, siis on täitja vormistatud adessiivis agentadverbiaalina.

Korraldustekstid on seega valdavalt suunatud korralduse andjale endale. Sellest tulenevalt aga ei ole neis esitatud protsessid alati oma tähenduselt sama konkreetsed, kui võiks eeldada verbivalikust lähtudes.

\section{Viidatud kirjandus}

Austin, John L. 1984. How to Do Things with Words. Oxford: Oxford University Press.

Erelt, Mati 1984. da-infinitiivi süntaktilised funktsioonid tänapäeva eesti keeles. Eesti NSV Teaduste Akadeemia Ühiskonnateaduste osakonna preprint KKI-24. Tallinn: Eesti NSV Teaduste Akadeemia.

Fowler, Roger 1991. Language in the News. Discourse and Ideology in the Press. London and New York: Routledge.

Halliday, M. A. K. 1994. An Introduction to Functional Grammar. Second edition. London: Arnold.

Kasik, Reet 2006. Nominaliseeritud protsessi agent meediauudistes. - Emakeele Seltsi aastaraamat, 51 (2005), 21-37.

Kukk, Inga 2003. Õiguse ja halduse keel. - Maire Raadik (toim.). Eesti kirjakeele kasutusvaldkondade seisundi uuring. Tallinna Pedagoogikaülikooli eesti filoloogia osakonna toimetised 4. Tallinn: TPÜ Kirjastus 96-117.

Leeuwen, T. van 1996. The representation of social actors. - C. R. Caldas-Coulthard, M. Coulthard (Eds.). Texts and Practices. London: Routledge, 32-70.

Metslang, Helle 2004. Imperative and related matters in everyday Estonian. - Linguistica Uralica, 4, 243-255.

Orav, Heili 1998. Eesti keele direktiivverbide semantilise välja struktuur tesaurusena. Magistritöö. Tartu Ülikool, eesti keele õppetool.

Searle, John R. 1970. Speech Acts: An Essay in the Philosophy of Language. Cambridge: Cambridge University Press. 


\section{Võrgumaterjalid}

Tartu Linnavalitsuse veebileht http://www.tartu.ee/?page_id=1257\&lang_id=1\&menu_ id=2\&lotus_url=/webaktid.nsf/WebKorraldused?OpenView\&Start=1\&Count=100\& RestrictToCategory=Tartu_Linnavalitsuse_2007.a._korraldused (16.02.2009).

Katrin Mandra (Tartu Ülikool) uurimisvaldkonnad on avaliku halduse keelekasutus, kriitiline tekstianalüüs.

katrin.mandra@ut.ee 


\section{THE STRUCTURE OF THE ADMINISTRATIVE TEXTS ON THE EXAMPLE OF TARTU CITY GOVERNMENT}

\section{Katrin Mandra}

University of Tartu

Administrative language is the written language used by administrative organizations and performed in administrative documents. These documents have the following functions: to affirm and impart information; to articulate and coordinate information.

The present article has three subjects in focus: syntactic structure of regulations as an example of administrative texts; functional classification of directive processes in these regulations and how the deontic agent (actor) is represented.

Two main features characterize the syntactic structure of regulations. Conjunctions are rarely used between clauses. One can feel an urge to package all the information into one sentence. Therefore infinitives, participles and nominalizations with their complements are frequently used. It makes the sentences long and complicates their structure.

Verbs impart processes in regulations. These processes are strongly tied in with the participants of the processes. If the city government subunits are represented as the deontic agent, material processes predominate. If the city government itself is the deontic agent, the represented processes are more abstract and more often mental or verbal.

City government is always represented as the deontic authority. Mostly they address the regulations to themselves and it makes responsibility bleary. Lesser regulations are addressed to the subunits and then the actions are more concrete. If the agents differ from the authority, they are formulated as agent-adverbials in the adessive case. The fewest are examples with individual agents or without agents at all.

Keywords: text linguistics, text types, functional grammar, syntax, Estonian 